\title{
Erratum to: Reactive aggression among children with and without autism spectrum disorder
}

\author{
Miia Kaartinen $^{1,2}$ - Kaija Puura ${ }^{1,2}$ - Mika Helminen ${ }^{3,4} \cdot$ Raili Salmelin $^{1,4}$. \\ Erja Pelkonen $^{1} \cdot$ Petri Juujärvi $^{5}$
}

Published online: 3 March 2017

(C) Springer Science+Business Media New York 2017

\section{Erratum to: J Autism Dev Disord (2014) 44: \\ 2383-2391 \\ DOI 10.1007/s10803-012-1743-1}

In the original publication, the data in Fig. 1 were accidently switched between impulsive aggression and controlled aggression. The figure has been corrected with this erratum.

The online version of the original article can be found under doi:10.1007/s10803-012-1743-1.

Miia Kaartinen

miia.kaartinen@fimnet.fi

1 Department of Child Psychiatry, Tampere University Hospital, Box 2000, 33521 Tampere, Finland

2 Department of Child Psychiatry, Medical School, University of Tampere, 33014 Tampere, Finland

3 Pirkanmaa Hospital District, Science Center, 33521 Tampere, Finland

4 Tampere School of Health Sciences, University of Tampere, 33014 Tampere, Finland

5 Department of Adolescent Psychiatry, Kuopio University Hospital, Box 1777, 70211 Kuopio, Finland 
Type of

aggression All attacks

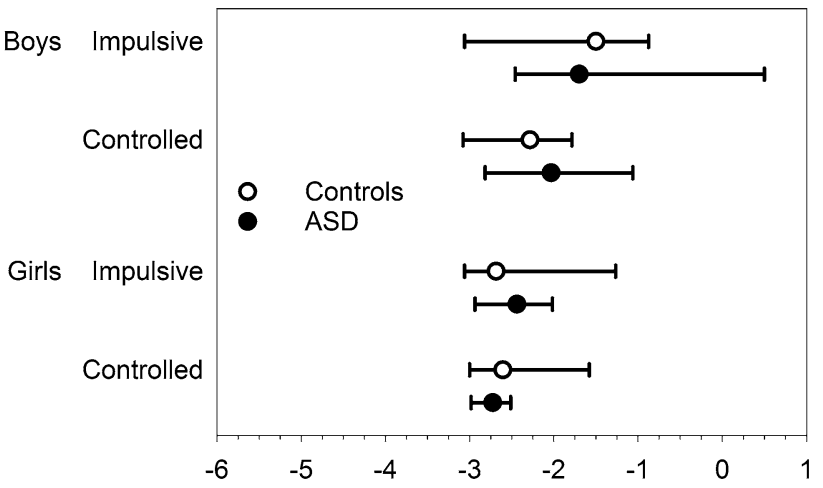

Minor attacks

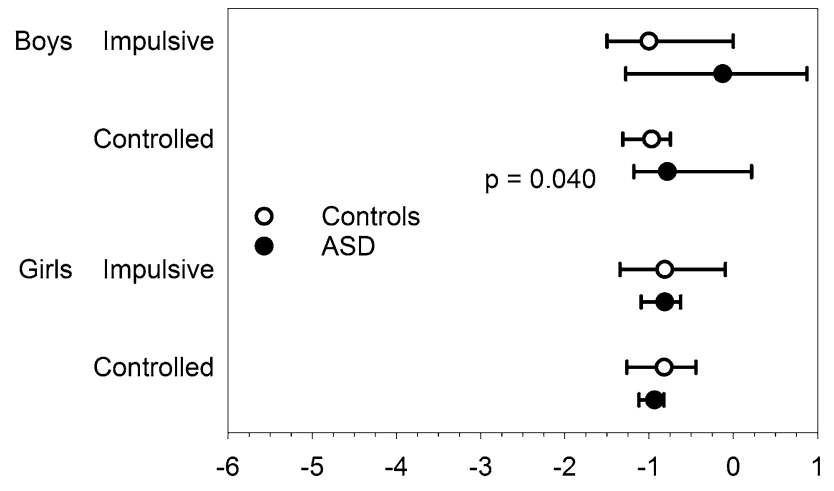

Major attacks

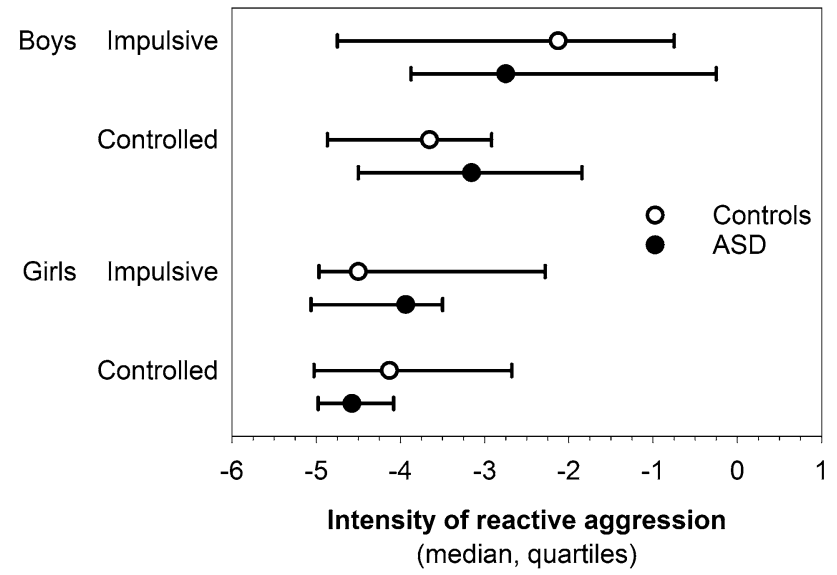

Fig. 1 Intensity of reactive aggression among participants 